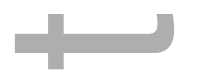

Article type : Original Article-Epidemiology of Allergic Disease

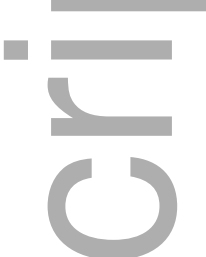

\title{
ATOPY IN PEOPLE AGED 40 AND OVER: RELATION TO AIRFLOW LIMITATION.
}

Elyse Marie Guevara-Rattray; elyse.guevara-rattray@sydney.edu.au, +61403169622

Respiratory Sleep and Environmental Health, Ingham Institute of Applied Medical Research Sydney, Australia. Orchid ID: orcid.org/0000-0002-7445-2873

Frances L. Garden: Respiratory Sleep and Environmental Health, Ingham Institute of Applied Medical Research Sydney, Australia.

Alan L. James: Department of Pulmonary Physiology and Sleep Medicine, Sir Charles Gairdner Hospital; School of Medicine and Pharmacology, University of Western Australia, Perth, Australia.

Richard Wood-Baker: School of Medicine, University of Tasmania, Hobart, Tasmania.

Michael J. Abramson: Department of Epidemiology and Preventive Medicine, Monash University Melbourne, Australia.

David P. Johns: University of Tasmania, Hobart, Australia

A. Sonia Buist: Pulmonary \& Critical Care Medicine, Oregon Health \& Science University, Portland, Oregon, USA

Peter G.J. Burney: Imperial College London, United Kingdom

E. Haydn Walters: Faculty of Health, University of Tasmania, Hobart, Australia

This is the author manuscript accepted for publication and has undergone full peer review but has not been through the copyediting, typesetting, pagination and proofreading process, which may lead to differences between this version and the Version of Record. Please cite this article as doi: $10.1111 /$ cea.13038

This article is protected by copyright. All rights reserved 
Brett G. Toelle: Respiratory and Environmental Epidemiology, Woolcock Institute of Medical Research, Sydney, Australia.

Guy B. Marks: Respiratory and Environmental Epidemiology, Woolcock Institute of Medical Research. South Western Sydney Clinical School, University of New South Wales, Australia.

Word count: 2344

Keywords: Atopy, airflow limitation, asthma, COPD, allergic sensitization, epidemiology, population health

ABSTRACT

Background: Previous studies have reached conflicting conclusions about the role of atopy as a risk factor for COPD. In part, this is attributable to variation in the definitions of airflow limitation and the treatment of people with asthma.

Objective: To establish whether there is any independent association between atopy and postbronchodilator airflow limitation in the general population aged 40 years and over.

Methods: A cross-sectional survey was conducted in a general population sample of 2415 people aged 40 years and over in Australia. A history of ever being diagnosed with asthma was elicited by questionnaire. Atopy was defined as any skin prick test wheal to common aero-allergens $\geq 4 \mathrm{~mm}$. Airflow limitation was defined as post-bronchodilator spirometric $\left(\mathrm{FEV}_{1} / \mathrm{FVC}\right)$ ratio < lower limit of normal. Analyses were adjusted for potential confounding due to age, sex, smoking, race and socioeconomic status.

Results: The prevalences of atopy, ever diagnosed asthma and post-bronchodilator airflow obstruction were $44.8 \%, 19.3 \%$ and $7.5 \%$, respectively. In the population as a whole, atopy was associated with lower $\mathrm{FEV}_{1}$ (adjusted difference $-0.068 \mathrm{~L}$, 95\% confidence interval(CI) -0.104 to 0.032), FVC (adj. difference $-0.043 \mathrm{~L}, 95 \% \mathrm{Cl}-0.086$ to -0.0009 ) and post-bronchodilator $\mathrm{FEV} / \mathrm{FVC}$ ratio (adj. difference $-0.011,95 \% \mathrm{Cl}-0.017$ to -0.0055 ). The effect of atopy on lung function was no longer apparent when participants who reported ever diagnosed asthma were excluded (FEV $-0.011 \mathrm{~L}$, [95\% $\mathrm{Cl}-0.05$ to $0.028 \mathrm{~L}$ ], $\mathrm{FVC}-0.012 \mathrm{~L}[95 \% \mathrm{Cl}-0.060$ to 0.036 ] and $\mathrm{FEV} / \mathrm{FVC}$ ratio -0.0012 [ $95 \% \mathrm{Cl}-0.0072$ to $0.0047 \mathrm{~L}])$.

Conclusion and Clinical Relevance: The apparent association between atopy and postbronchodilator airflow limitation in the general population appears to be explained by the association between atopy and having ever diagnosed asthma and the effect of asthma on lung function.

\section{INTRODUCTION}

This article is protected by copyright. All rights reserved 
Atopy or allergy is commonly associated with the asthma phenotype and with the presence of respiratory symptoms, including chronic cough, phlegm and wheeze [1]. A number of early epidemiological studies showed that atopy was not associated with the presence of fixed airflow limitation, [2, 3] whereas later population studies reported an independent association between atopy and GOLD-defined COPD[4], atopy and both lower levels of FEV ${ }_{1}[5]$ and accelerated rates of decline in $\mathrm{FEV}_{1}$ and $\mathrm{FEV}_{1} / \mathrm{FVC}$ ratio[6]. Furthermore, symptoms that are commonly linked to COPD, such as cough and sputum production[7] and exacerbations of COPD[8] are both associated with the presence of atopy. Hence, there remain unanswered questions about the nature of the association of atopy and COPD.

Many of the earlier population studies examining the relation between atopy and airway obstruction have relied on pre-bronchodilator $\mathrm{FEV}_{1}$ as an index of airflow limitation[2, 3, 5] and have excluded people with self-reported asthma[2, 3, 6, 7, 9]. This is problematic because excluding people with asthma may have removed some people who might also be defined as having "COPD". Prebronchodilator spirometry may be influenced by the effect of bronchoconstriction related to asthma, even when people with known asthma are excluded. Hence, there are no existing general population-based studies that have assessed the association between allergic sensitisation and postbronchodilator airflow limitation. The aim of this study was to establish whether there was any association between atopy and post-bronchodilator airflow limitation in the general population aged 40 years and over, and if such an association existed, to establish whether it was independent of ever having a diagnosis of asthma.

\section{METHODS}

The Australian Burden of Obstructive Lung Diseases (BOLD) study was conducted in a representative sample of adults aged 40 years and over living in six diverse locations in four states, in major metropolitan, regional, rural and remote locations around Australia. The prevalence of obstructive airways disease as measured in those locations has been reported previously[10]. Here we report additional data on atopy and its relation to spirometric function. Atopy was measured using allergen skin prick tests in five of the six Australian BOLD centres.

The study was approved by Human Research Ethics Committees of the University of Sydney, Ref No. 12-2006/9724. In addition, all sites obtained their own local ethics approvals to ensure any site specific local requirements were observed. All participants gave written informed consent.

\section{Sampling plan and recruitment}


The electoral roll was used to select a random, gender stratified sample for four sites: Melbourne, rural NSW, Sydney and Tasmania. In Busselton, participants who were initially drawn from the electoral roll and who participated in a previous study were re-invited to participate in this study (Table 1). Details of the selection process have been published[10] All eligible individuals in these five study centres initially received a letter inviting them to participate and if interested, to telephone for an appointment. After two weeks, study staff telephoned those individuals who had not made contact and made a number of further attempts to contact by telephone or mail. All participants gave written informed consent.

Those who declined to participate in the study were asked to complete a brief questionnaire. This included only questions about age, respiratory illness and smoking status.

\section{Study questionnaire}

We used the BOLD study questionnaire[11, 12] in all study centres. The questionnaire was administered in English by interview at all sites. 'Ever asthma' was defined as a positive response to the question 'Has a doctor or other health care provider ever told you that you have asthma, asthmatic bronchitis or allergic bronchitis?'. 'Current asthma' was defined as having 'ever asthma' and also a positive response to the question 'Do you still have asthma, asthmatic bronchitis or allergic bronchitis?',

\section{Measurement of spirometric lung function}

We performed spirometry on all participants (unless contraindicated or technically unable) using the EasyOne Spirometer (ndd Medizintechnik, Zürich, Switzerland)[11]. Spirometry was performed before and at least $15 \mathrm{~min}$ after administration of salbutamol $200 \mu \mathrm{g}$ via metered dose inhaler and spacer. Participants were requested to withhold LABA and LAMA for 12 hours before spirometry.

All spirograms were reviewed by a respiratory scientist and assigned a quality score based on published acceptability and repeatability criteria[13]. Data for forced expiratory volume in 1 second $\left(\mathrm{FEV}_{1}\right)$ and forced vital capacity (FVC) were deemed usable and included in this analysis if they fully met European Respiratory Society (ERS)/American Thoracic Society (ATS) acceptability criteria and were repeatable to within $200 \mathrm{~mL}$. Study personnel responsible for performing spirometry were certified before the start of data collection and received regular feedback about test quality during data collection.

The highest recorded FEV $\mathrm{F}_{1}$ and FVC from acceptable breaths were used in the analysis. Participants were considered to have post-bronchodilator airflow limitation if the $\mathrm{FEV}_{1} / \mathrm{FVC}$ ratio $<$ the lower limit of normal (LLN) for their age, height and sex[14]. To allow comparison with previously published results, the prevalence of airflow limitation defined as post-bronchodilator $\mathrm{FEV}_{1} / \mathrm{FVC}$ ratio $<0.70[14]$ is also presented. "Reversibility" was defined as a post-bronchodilator increase in FEV1 of 
$\geq 12 \%$ of the pre-bronchodilator value and $\geq 200 \mathrm{~mL}$. "Reversibility consistent with asthma" was defined reversibility in a participant with pre-bronchodilator airflow limitation (that is, prebronchodilator FEV1/FVC ratio <LLN).

\section{Allergic Sensitization}

We measured atopy using skin prick tests to nine common aeroallergens including Dermatophagoides pteronyssinus, D. farinae (house dust mites), cat, dog, cockroach, Alternaria, Aspergillus, ryegrass, and mixed grass pollen (Hollister-Stier, Spokane, WA). Glycerol and histamine phosphate $10 \mathrm{mg} / \mathrm{ml}$ were used as negative and positive controls, respectively. Participants were requested to withhold antihistamine medication 48 hours prior to testing. The skin prick test was performed by placing a small drop of allergen onto the participant's forearm and then the skin was pricked via a sterile lancet through the allergen extract [15]. Wheal sizes were measured 15 minutes later and those that were $\geq 4 \mathrm{~mm}$ and $>$ negative control were classified as a positive test for that allergen[16]. Participants with one or more positive allergen wheal were classified atopic. Those with no positive allergen wheals were classified as non-atopic, unless their histamine wheal was also < $4 \mathrm{~mm}$, in which case the test was regarded as invalid.

\section{ANALYSIS}

Participants included in this analysis had: (1) valid skin prick test results (2), completed the survey and (3) performed acceptable quality post-bronchodilator spirometry. We used the Global Lung function Initiative (GLI) 2012 equations to calculate the lower limit of normal for the $F E V_{1} / F V C$ ratio[14]. Data were analysed using SAS 9.4 (SAS Institute Inc., Cary, NC, USA). Univariate (descriptive) and multivariate analyses were performed. The relationship between atopy and lung function was assessed by a linear regression model. All FEV ${ }_{1}$ and FVC models were adjusted for age, sex and height, and the ratio of $\mathrm{FEV}_{1} / \mathrm{FEV}$ models were adjusted for age and sex. Additional analyses also adjusted for smoking, race and Socio-Economic Indexes for Areas (SEIFA). SEIFA is a locationbased measure of socio-economic disadvantage that ranks areas in Australia according to the relative socio-economic advantage and disadvantage and is based upon information gathered at the five-yearly Australian census[17].

Results are reported both for the whole sample and also after excluding those who reported ever being diagnosed with asthma.

\section{RESULTS}

Of the 10,348 adults initially included in the BOLD Australia sampling frame, 2618 had valid skin prick test results, and 2604 also completed the BOLD questionnaire. From this sample, 2415 (92\%) had also performed acceptable post-bronchodilator spirometry and were included in the present This article is protected by copyright. All rights reserved 
analysis. The study population comprised approximately 50\% females and the average age was nearly 60 years (Table 1 ). Just over one quarter $(25.7 \%)$ of participants were in the least disadvantaged SEIFA quintile and $<10 \%$ were in the most disadvantaged quintile. Over two thirds (72.2\%) were either overweight or obese, defined as a $\mathrm{BMI} \geq 25 \mathrm{~kg} / \mathrm{m}^{2}$. Fifty percent of the study population had never smoked and $18.6 \%$ had smoked more than 20 pack-years. Comparisons of the study sample with the Australian population aged $\geq 40$ years are shown in Supplementary Table 1.

Table 1: Characteristics of the study sample $\mathrm{N}=2415$

\begin{tabular}{ll}
\hline Characteristic & $\mathrm{n}(\%)$ \\
\hline Gender (female) & $1215(50.3 \%)$ \\
Age (years) (mean (SD)) & $59.9(11.9)$ \\
Socio-Economic Indexes for Areas (SEIFA) & \\
Quintile 5 (least disadvantaged) & $621(25.7 \%)$ \\
Quintile 4 & $294(12.2 \%)$ \\
Quintile 3 & $1033(42.8 \%)$ \\
Quintile 2 & $235(9.7 \%)$ \\
Quintile 1 (most disadvantaged) & $231(9.6 \%)$ \\
Caucasian & $2317(96.0 \%)$ \\
Body Mass Index (BMI) & \\
Normal (BMI <25) & $670(27.8 \%)$ \\
Overweight/obese (BMI $\geq 25)$ & $1743(72.2 \%)$ \\
Smoking pack years & \\
Never smoked & $1222(50.6 \%)$ \\
$<10$ pack years & $487(20.2 \%)$ \\
$10 \leq$ pack years<20 & $256(10.6 \%)$ \\
$\geq 20$ pack years & $449(18.6 \%)$ \\
\hline
\end{tabular}

Nearly $20 \%$ of participants reported 'ever asthma', ever diagnosed with asthma by a doctor or health professionaland $6.0 \%$ reported a doctor or health professional diagnosis of COPD (Table 2). Of the sample, $2.5 \%$ were classified as having bronchodilator reversibility consistent with asthma (as defined above). Of those ever diagnosed with asthma, $25.1 \%$ had pre-bronchodilator airflow limitation, $6.2 \%$ had bronchodilator reversibility, and $18.6 \%$ had post-bronchodilator airflow limitation. Among those with post-bronchodilator airflow limitation, 54\% were atopic.

Table 2. Respiratory outcomes of the study sample $\mathrm{N}=2415$

Characteristics Mean (SD) or $\mathrm{n}(\%)$

Mean spirometric measurements

This article is protected by copyright. All rights reserved 
$\mathrm{FEV}_{1}$ post-bd (L)(mean (SD))

$2.89(0.85)$

FVC post-bd (L)(mean (SD))

$3.74(1.02)$

$\mathrm{FEV}_{1} / \mathrm{FVC}$ post bd ratio (mean (SD))

$0.77(0.08)$

Pre-bd airflow limitation $\left(\mathrm{FEV}_{1} / \mathrm{FVC}\right.$ ratio < LLN [GLI])

Reversibility consistent with asthma**

Ever asthma

...and (pre-bd FEV ${ }_{1} / \mathrm{FVC}$ ratio < LLN [GLI])

...and (reversibility consistent with asthma)**

...and (post-bd FEV $1 /$ FVC ratio < 0.7 )

...and (post-bd FEV $1 /$ FVC ratio < LLN [GLI])

...and current asthma

...and reversibilityo

...and atopy

Current asthma

Self-reported doctor diagnosed COPD

Post-bd FEV 1 /FVC ratio < LLN [GLI]

Post-bd FEV $1 /$ FVC ratio $<0.7$

...and reversibilityo

...and atopy

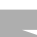

LLN=lower limit normal

$\mathrm{GLI}=$ Global Lung function Initiative

bd=bronchodilator

$* *$ pre-bd airflow limitation (pre-bd FEV $1 / F V C$ ratio $<L L N$ ) and reversibility (post-bd increase in $\mathrm{FEV}_{1}$ of $\geq 12 \%$ of the pre-bd value and $\geq 200 \mathrm{ml}$ )

$\diamond$ post-bd increase in $\mathrm{FEV}_{1}$ of $\geq 12 \%$ of the pre-bd value and $\geq 200 \mathrm{ml}$

Nearly half of the study sample were atopic by skin prick test. The most common allergen to which participants were sensitised was house dust mite (Table 3).

Table 3. Proportion of participants with positive skin prick tests $\mathrm{N}=2415$

\begin{tabular}{ll}
\hline Characteristic of Atopic ${ }^{\ddagger}$ population & \multicolumn{1}{c}{$\mathrm{n}(\%)$} \\
\hline Any one or more positive skin prick tests (atopic) & $1083(44.8 \%)$ \\
D. pteronyssinus & $696(28.9 \%)$ \\
D. farinae & $580(24.1 \%)$ \\
Cat & $169(7.0 \%)$ \\
Dog & $54(2.2 \%)$ \\
Cockroach & $192(8.0 \%)$
\end{tabular}

This article is protected by copyright. All rights reserved
$60(2.5 \%)$

$467(19.3 \%)$

$117 / 467(25.1 \%)$

$29 / 467(6.2 \%)$

$113 / 467(24.2 \%)$

$87 / 467(18.6 \%)$

256/465 (55.1\%)

51/467 (10.9\%)

$305 / 467$ (65.3\%)

256 (10.6\%)

144 (6.0\%)

181 (7.5\%)

366 (15.2\%)

44/181 (24.3\%)

98/181 (54.1\%) 
${ }^{\ddagger}$ A positive skin prick test was defined as a wheal size $\geq 4 \mathrm{~mm}$ and $>$ negative control

Participants with 'ever asthma' had lower post bronchodilator $\mathrm{FEV}_{1}, \mathrm{FEV}_{1} / \mathrm{FVC}$ ratio and FVC than participants without 'ever asthma' (Table 4). The effect of asthma status on FEV ${ }_{1}(P=0.02$ for sex-byasthma status interaction term) and $\mathrm{FEV}_{1} / \mathrm{FVC}(\mathrm{P}=0.01)$, but not on FVC $(P=0.82)$, differed between men and women but was highly significant in both.

Table 4: Association between 'ever asthma' and post bronchodilator spirometry, adjusted ${ }^{\ddagger}$ for confounders

\section{Spirometric measure}

Adjusted mean difference

$(95 \% \mathrm{Cl})$

Asthma minus no asthma

\begin{tabular}{lll} 
& Asthma minus no asthma & \\
\hline All persons & & $<0.0001$ \\
\hline FEV $_{1}$ post-bd & $-0.23 \mathrm{~L}(-0.27$ to -0.19$)$ & $<0.0001$ \\
FVC post-bd & $-0.11 \mathrm{~L}(-0.17$ to -0.060$)$ & $<0.0001$ \\
FEV 1 /FVC ratio post-bd & $-0.042(-0.049$ to -0.035$)$ & \\
& & \\
Females & & $<0.0001$ \\
FEV 1 post-bd & $-0.19 \mathrm{~L}(-0.24$ to -0.14$)$ & $<0.0001$ \\
FVC post-bd & $-0.12 \mathrm{~L}(-0.18$ to -0.07$)$ & $<0.0001$ \\
FEV 1 FVC ratio post-bd & $-0.035(-0.044$ to -0.026$)$ & \\
& & $<0.0001$ \\
Males $_{\text {FEV }}$ post-bd & $-0.30 \mathrm{~L}(-0.37$ to -0.22$)$ & $<0.0001$ \\
FVC post-bd & $-0.11 \mathrm{~L}(-0.21$ to -0.02$)$ & $<0.0001$ \\
FEV ${ }_{1} /$ FVC ratio post-bd & $-0.053(-0.065$ to -0.042$)$ &
\end{tabular}

\footnotetext{
${ }^{\ddagger}$ Adjusted for: age, sex, height, sex*age, sex*height interaction, race, SEIFA, smoking status. Ratio is not adjusted for height ${ }^{\text {t}} \mathrm{P}$-value: from a linear regression model
}

This article is protected by copyright. All rights reserved 
In the full study population, post-bronchodilator $\mathrm{FEV}_{1}, \mathrm{FEV}_{1} / \mathrm{FVC}$ ratio and FVC were all lower in participants with atopy than in those without atopy (Table 5). However, in the population excluding those with 'ever asthma', there was no significant association between atopy and post-

bronchodilator spirometric function. The effects of atopy did not differ between men and women (all interaction $p$ values $>0.05$ ).

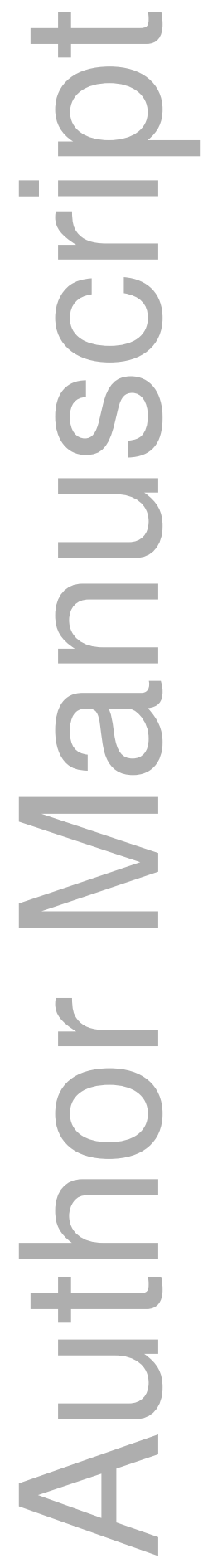


Table 5: Influence of atopy on post bronchodilator spirometric function, presented as mean difference in litres

$(95 \% \mathrm{Cl})$ between those with atopy and without atopy

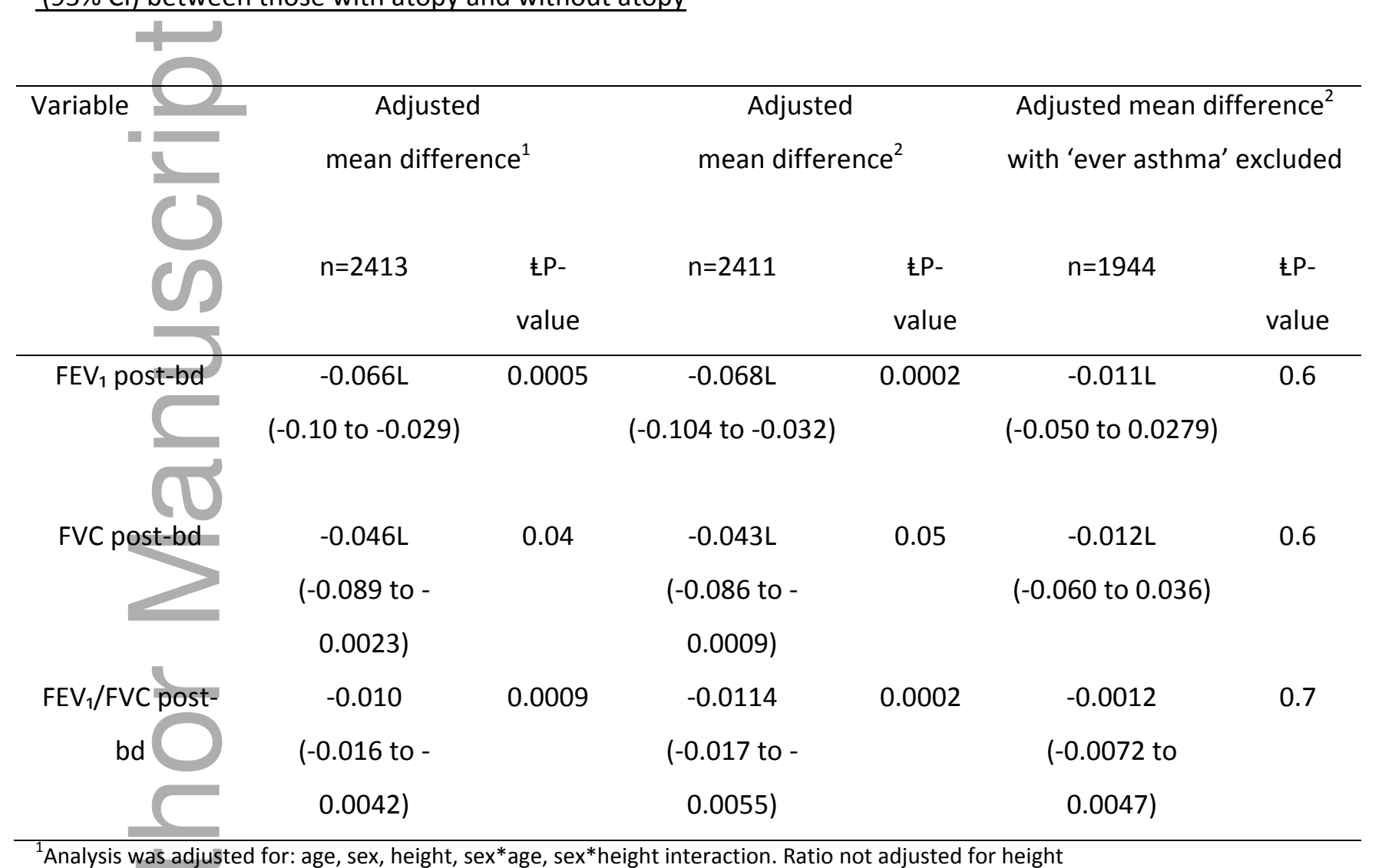

${ }^{1}$ Analysis was adjusted for: age, sex, height, sex*age, sex*height interaction. Ratio not adjusted for height

${ }^{2}$ Adjusted for: age, sex, height, sex*age, sex*height interaction, race, SEIFA, smoking status. Ratio not adjusted for height

ŁP-value: from a linear regression model

Mean difference $=$ atopy minus no atopy

This article is protected by copyright. All rights reserved 


\section{DISCUSSION}

We have shown that there is a cross-sectional association between atopy and post-bronchodilator airflow limitation in the general population as a whole. However, when participants who report ever being diagnosed with asthma are excluded there is no evidence of an association between atopy and either airflow limitation or reduced spirometric lung volumes.

Our study findings are consistent with previous studies showing that a diagnosis of asthma is associated with reduced lung function that is evident in early life $[18,19]$ and at the beginning of adult life [20] and with a small increase in the rate of decline in lung function in adult life[19-22]. Since asthma is clearly linked to atopy, it not surprising that, in a mixed population of people with airflow limitation that includes a substantial proportion with a history of asthma, any association of atopy with airflow limitation would be confounded by asthma. The important finding of this study is that, when people who reported ever being diagnosed with asthma were excluded, there was no association with between atopy and post-bronchodilator airflow limitation in the remaining population. This is consistent with a more recent meta-analysis of a European multi-centre study that demonstrated that participants with atopy did not have lower lung function[23].

Earlier studies had reported that, when asthma was excluded, allergic sensitisation was not associated with airflow limitation[2, 3, 9]. However, these studies did not measure postbronchodilator airflow obstruction and hence could have been confounded by factors leading to transient bronchoconstriction, including triggers for asthma[3, 24]. In contrast, the Normative Ageing Study[3, 6, 9] showed that in men with a mean age of 61 who denied any history of asthma, the presence of atopy was associated with additional $9.5 \mathrm{~mL}$ in the annual rate of decline in $\mathrm{FEV}_{1}$ compared with people without atopy, implying that atopy may have a causal role in the aetiology of COPD[6]. However, that study population differed from the present study in that people with all forms of obstructive lung diseases or other chronic illnesses at baseline were excluded.

The present study is based on a sample of the general population and the findings may be more generalizable. A recent Australian population study has shown that among atopic, but not nonatopic, people there was synergistic interaction between smoking and a history of asthma in causing post-bronchodilator airflow limitation[25]. However, although this demonstrated effect modification attributable to atopic status, the authors did not report the direct effect of atopic status on the risk of having airflow limitation. Hence, there are few other data that allow direct assessment of effect of atopy on the risk of post-bronchodilator airflow obstruction, independent of asthma.

This article is protected by copyright. All rights reserved 
Our study was based on large general population samples from different geographical regions around Australia. We implemented a standardized protocol across all sites with rigorous attention to quality control procedures for skin prick tests, performance of spirometry and administration of the questionnaire. We measured pre- and post-bronchodilator spirometry. The low participation rate is a potential limitation leading to the risk of selection bias for prevalence estimates. We have shown that, compared with the Australian population aged $\geq 40$ years, those in the sample were less likely to be aged $\geq 75$ years (among women), or less likely to live in the most socioeconomically disadvantaged areas, remote areas, and be Aboriginal or Torres Strait Islanders. However, we believe it is unlikely to have influenced the association between atopy and airflow limitation, which was the major focus of this study. We chose a broad question to identify the asthma population using 'ever asthma' for analysis to try capture as many of those with a history of asthma. However this self-report may have failed to exclude those who forgot they had asthma in childhood. More importantly, excluding people with 'ever asthma' may have excluded some people with obstructive airways disease who did not, in fact, have asthma. If atopic people with COPD were more likely than non-atopic people with COPD to be diagnosed as "asthma" because of the presence of other features of the atopic syndrome, such as allergic rhinitis or eczema, then incorrectly excluding these participants would tend to underestimate the association between atopy and COPD. Unfortunately, there is no analytical approach to resolving this problem using cross-sectional data. Greater understanding of this issue will require long-term follow-up of child cohorts in which both asthma status and atopic status have been carefully defined.

In conclusion, we have confirmed that, overall, post-bronchodilator airflow limitation in adults aged over 40 is associated with the presence of atopy. However, it is a heterogeneous condition. In part, that heterogeneity is explained by asthma, which is associated with atopy and is known to have long-term effects on lung function. However, there remains some uncertainty about the past diagnosis of asthma in cross-sectional studies such as this and long-term follow-up of well characterised child cohorts will be required to fully resolve the question.

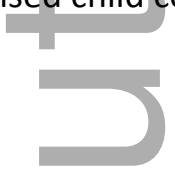

Acknowledgements: We would like to acknowledge the following people involved in the data collection for the Australian BOLD study Deborah L Burton, Tessa E Bird, Wei Xuan, Christine R Jenkins, Kate Hardaker, Paola Espinel, A W (Bill) Musk, Michael L Hunter, Elspeth Inglis, Peta Grayson, Angela Lewis, Joan Raven, Joan Green, Marsha Ivey, Carol Phillips, Loren Taylor, Phillipa J Southwell, Bruce J Graham, Brian Spurrell, Robyn Paton, Melanie Heine, Cassandra Eccleston, Julie Cooke. Funding was from the National Health and Medical Research Council of Australia. MJA holds 
investigator initiated grants from Pfizer and Boehringer-Ingelheim for unrelated research. The other authors have no competing interests

\section{References}

1. Mensinga TT, Schouten JP, Rijcken B, Weiss ST, Speizer FE, van der Lende R. The relationship of eosinophilia and positive skin test reactivity to respiratory symptom prevalence in a communitybased population study. J Allergy Clin Immunol 1990: 86(1): 99-107.

2. Burrows B, Knudson RJ, Cline MG, Lebowitz MD. A reexamination of risk factors for ventilatory impairment. American Review of Respiratory Disease 1988: 138(4): 829-836.

3. Parker DR, O'Connor GT, Sparrow D, Segal MR, Weiss ST. The relationship of nonspecific airway responsiveness and atopy to the rate of decline of lung function. The Normative Aging Study. American Review of Respiratory Disease 1990: 141(3): 589-594.

4. Shirtcliffe P, Marsh S, Travers J, Weatherall M, Beasley R. Childhood asthma and GOLDdefined chronic obstructive pulmonary disease. Internal Medicine Journal 2012: 42(1): 83-88.

5. Mensinga TT, Schouten JP, Weiss ST, Van der Lende R. Relationship of skin test reactivity and eosinophilia to level of pulmonary function in a community-based population study. American Review of Respiratory Disease 1992: 146(3): 638-643.

6. Gottlieb DJ, Sparrow D, O'Connor GT, Weiss ST. Skin test reactivity to common aeroallergens and decline of lung function. The Normative Aging Study. American Journal of Respiratory \& Critical Care Medicine 1996: 153(2): 561-566.

7. Fattahi F, ten Hacken NHT, Löfdahl C-G, Hylkema MN, Timens W, Postma DS, Vonk JM. Atopy is a risk factor for respiratory symptoms in COPD patients: results from the EUROSCOP study. Respiratory Research 2013: 14(1): 10-10.

8. Jamieson DB, Matsui EC, Belli A, McCormack MC, Peng E, Pierre-Louis S, Curtin-Brosnan J, Breysse PN, Diette GB, Hansel NN. Effects of allergic phenotype on respiratory symptoms and exacerbations in patients with chronic obstructive pulmonary disease. American Journal of Respiratory \& Critical Care Medicine 2013: 188(2): 187-192.

9. O'Connor GT, Sparrow D, Segal M, Weiss ST. Risk Factors for Ventilatory Impairment Among Middle-Aged and Elderly Men: The Normative Aging Study. Chest 1993: 103(2): 376-382.

10. Brett G Toelle WX, Tessa E Bird, Michael J Abramson, David N Atkinson, Deborah L Burton, Alan L James, Christine R Jenkins, David P Johns, Graeme P Maguire, A W (Bill) Musk, E Haydn Walters, Richard Wood-Baker, Michael L Hunter, Bruce J Graham, Phillipa J Southwell, William M 
Vollmer, A Sonia Buist and Guy B Marks. Respiratory symptoms and illness in older Australians: the Burden of Obstructive Lung Disease (BOLD) study. Medical Journal of Australia 2013(198): 3.

11. Buist AS, Vollmer WM, Sullivan SD, Weiss K, Lee TA, Menezes A, Crapo RO, Jensen RL, Burney $P$. The Burden of Obstructive Lung Disease initiative (BOLD): rationale and design. COPD: Journal of Chronic Obstructive Pulmonary Disease 2005: 2(2): 277-283.

12. Buist AS, McBurnie MA, Vollmer WM, Gillespie S, Burney P, Mannino DM, Menezes AM, Sullivan SD, Lee TA, Weiss K, Jensen RL, Marks GB, Gulsvik A, Nizankowska-Mogilnicka E. International variation in the prevalence of COPD (the BOLD Study): a population-based prevalence study. Lancet 2007: 370: 741-750.

13. Miller MR, Hankinson J, Brusasco V, Burgos F, Casaburi R, Coates A, Crapo R, Enright P, van der Grinten CP, Gustafsson P, Jensen R, Johnson DC, Maclntyre N, McKay R, Navajas D, Pedersen OF, Pellegrino R, Viegi G, Wanger J, Force AET. Standardisation of spirometry. European Respiratory Journal 2005: 26(2): 319-338.

14. Quanjer PH, Stanojevic S, Cole TJ, Baur X, Hall GL, Culver BH, Enright PL, Hankinson JL, Ip MSM, Zheng J, Stocks J. Multi-ethnic reference values for spirometry for the 3-95-yr age range: the global lung function 2012 equations. European Respiratory Journal 2012: 40(6): 1324-1343.

15. Pepys J. Skin Testing. British Journal of Hospital Medicine 1975(October): 412-417.

16. Peat JK, Salome CM, Woolcock AJ. Longitudinal changes in atopy during a 4-year period: Relation to bronchial hyperresponsiveness and respiratory symptoms in a population sample of Australian schoolchildren. Journal of Allergy and Clinical Immunology 1990: 85(1): 65-74.

17. Australian Bureau of Statistics. 2008 26/03/2008 [cited 2016 26/09]; Available from: http://www.abs.gov.au/ausstats/abs@.nsf/mf/2039.0

18. Williams H, McNicol KN. Prevalence, natural history, and relationship of wheezy bronchitis and asthma in children. An epidemiological study. British Medical Journal 1969: 4(5679): 321.

19. Sears MR, Greene JM, Willan AR, Wiecek EM, Taylor DR, Flannery EM, Cowan JO, Herbison GP, Silva PA, Poulton R. A Longitudinal, Population-Based, Cohort Study of Childhood Asthma Followed to Adulthood. New England Journal of Medicine 2003: 349(15): 1414-1422.

20. Lange P, Parner J, Vestbo J, Schnohr P, Jensen G. A 15-Year Follow-up Study of Ventilatory Function in Adults with Asthma. New England Journal of Medicine 1998: 339(17): 1194-1200.

21. Tai A, Tran H, Roberts M, Clarke N, Gibson A-M, Vidmar S, Wilson J, Robertson CF. Outcomes of childhood asthma to the age of 50 years. Journal of Allergy and Clinical Immunology 2014: 133(6): 1572-1578.e1573.

This article is protected by copyright. All rights reserved 
22. James AL PL, Kicic E, Maxwell PS, Lagan SE, Ryan GF et al. Decline in lung function in the Busselton health study: The effects of asthma and cigarette smoking. American Journal of Respiratory and Critical Care Medicine 2005: 171(109-14).

23. Obaseki D, Potts J, Joos G, Baelum J, Haahtela T, Ahlstrom M, Matricardi P, Kramer U, Gjomarkaj M, Fokkens W, Makowska J, Todo-Bom A, Toren K, Janson C, Dahlen SE, Forsberg B, Jarvis D, Howarth P, Brozek G, Minov J, Bachert C, Burney P, excellence GLno. The relation of airway obstruction to asthma, chronic rhinosinusitis and age: results from a population survey of adults. Allergy: 69(9): 1205-1214.

24. Burrows B, Bloom JW, Traver GA, Cline MG. The Course and Prognosis of Different Forms of Chronic Airways Obstruction in a Sample from the General Population. New England Journal of Medicine 1987: 317(21): 1309-1314.

25. Perret JL, Dharmage SC, Matheson MC, Johns DP, Gurrin LC, Burgess JA, Marrone J, Markos J, Morrison S, Feather I, Thomas PS, McDonald CF, Giles GG, Hopper JL, Wood-Baker R, Abramson MJ, Walters EH. The interplay between the effects of lifetime asthma, smoking, and atopy on fixed airflow obstruction in middle age. American Journal of Respiratory \& Critical Care Medicine: 187(1): $42-48$.

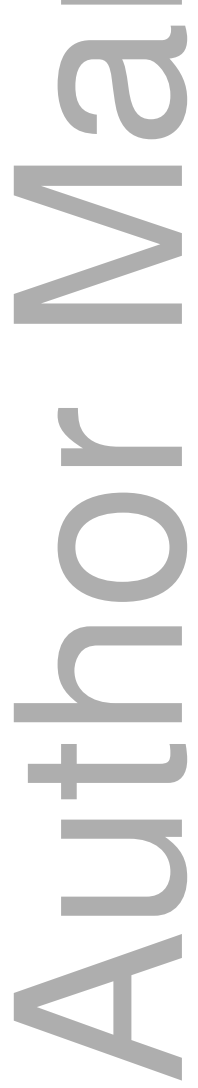




\section{University Library}

\section{- M I N E R VA}

\section{A gateway to Melbourne's research publications}

Minerva Access is the Institutional Repository of The University of Melbourne

\section{Author/s:}

Guevara-Rattray, EM;Garden, FL;James, AL;Wood-Baker, R;Abramson, MJ;Johns, DP;Buist, AS;Burney, PGJ;Walters, EH;Toelle, BG;Marks, GB

Title:

Atopy in people aged 40 years and over: Relation to airflow limitation

\section{Date:}

2017-12-01

\section{Citation:}

Guevara-Rattray, E. M., Garden, F. L., James, A. L., Wood-Baker, R., Abramson, M. J., Johns, D. P., Buist, A. S., Burney, P. G. J., Walters, E. H., Toelle, B. G. \& Marks, G. B. (2017). Atopy in people aged 40 years and over: Relation to airflow limitation. CLINICAL AND EXPERIMENTAL ALLERGY, 47 (12), pp.1625-1630. https://doi.org/10.1111/cea.13038.

Persistent Link:

http://hdl.handle.net/11343/293818 